\title{
Simulação de processo para tratamento de óleos ácidos e produção de biodiesel
}

\author{
Bruna Ricetti Margarida*, Luiz Fernando de Lima Luz Jr* \\ 1 - Departamento de Engenharia Química, Universidade Federal do Paraná - UFPR - PR, \\ Caixa Postal 19011 - Centro Politécnico - CEP81531-980 - ricetti@ufpr.br
}

Resumo - Com a crescente demanda por combustíveis de fontes renováveis, a busca por novos métodos e aperfeiçoamento dos já existentes deve ser explorada. O processo de produção de biodiesel está em ascensão no país e, com estímulos à produção e utilização do mesmo, é de grande interesse o uso de ferramentas computacionais de modo a poder prever quais as necessidades e obstáculos a serem superados no processo, além de poder-se ter uma estimativa de custos e resultados, de forma que se tenha uma fonte confiável para a tomada da melhor decisão. Neste trabalho foram feitos experimentos em escala laboratorial para a determinação das condições para a reação de esterificação, além da obtenção dos dados necessários para a simulação. Com os resultados, realizou-se o ajuste dos parâmetros para representar a cinética da reação e, em seguida, a simulação do processo de produção de biodiesel a partir de correntes oleosas ricas em ácidos graxos. Os resultados apresentados são promissores e podem contribuir para a obtenção de biodiesel de fontes residuais e não a partir de óleos comestíveis.

Palavras-chave: biodiesel, ácidos graxos, ácido láurico, simulação, esterificação e transesterificação. 


\section{Introdução}

Com a contínua busca por novas fontes de energia e o aprimoramento dos processos, o uso de modelagem e simulação ganha destaque, uma vez que o uso de ferramentas computacionais torna mais simples, rápidas e com uma boa predição as análises de qualidade, demanda e custo. Portanto o estudo de um aperfeiçoamento de operações já existentes é relevante e de interesse, pois pode auxiliar a identificar problemas prévios e estimar se o que está sendo proposto é economicamente viável.

Uma fonte de energia com crescimento de demanda é o biodiesel, sendo tanto este quanto o etanol os principais tipos de biocombustíveis produzidos e utilizados no setor de transportes brasileiro [1]. O crescimento do uso do biodiesel no país também pode ser verificado no estímulo ao seu uso e, por consequência, a produção deste, como demanda a Lei $\mathrm{n}^{\circ} 13.263 / 2016$, a qual estabelece os percentuais de adição de biodiesel ao óleo diesel comercializado em território nacional, sendo autorizada a adição de $10 \%$ até 2019, em volume, de biodiesel. Com isso, a produção de biodiesel em território nacional está se tornando cada vez mais importante, o que auxilia na geração de empregos, estimula o mercado interno e aumenta as riquezas do país. Com o uso do processo de esterificação e transesterificação, como proposto no trabalho, outras correntes ricas em óleos, porém com a presença de ácidos graxos livres, podem também ser viabilizadas para a produção de biodiesel.

Combustíveis largamente utilizados atualmente, como a gasolina e o diesel, são derivados do petróleo, portanto há incertezas com relação ao mercado no futuro, além da disponibilidade do recurso. O biodiesel por sua vez é obtido a partir do óleo vegetal ou gordura animal, auxiliando na estabilidade no mercado deste produto e também na melhor previsão sobre a obtenção de matéria prima e, por consequência, na sua produção.

Ainda que existam diversos processos distintos para a produção de biodiesel, o abordado neste trabalho envolve a reação de esterificação envolvendo uma mistura óleo-ácido graxo, onde o ácido láurico representa os ácidos graxos livres presentes em resíduos oleosos [2], e etanol (80\% molar). Mesmo com o maior teor de água presente, o processo proposto apresentou resultados satisfatórios mesmo em condições mais brandas. Após a esterificação segue-se com o processo convencional de transesterificação em meio básico para a produção de biodiesel. O uso de catalisador básico para a reação de transesterificação é recomendado por necessitar de condições menos energéticas, menor tempo e menores quantidades de álcool para a ocorrência da reação [3].

O álcool utilizado para ambas as reações, de esterificação e transesterificação, foi o etanol. Embora grande parte dos processos ainda sejam realizados com metanol ou uma mistura metanol/etanol por ser mais simples, o uso de etanol para a formação de ésteres possui a vantagem de gerar compostos com melhores características combustíveis [4]. O uso de etanol, analisando agora a situação do Brasil, em que há elevada produção deste álcool, é vantajoso pois seu preço passa a ser competitivo com relação ao do metanol, além disso, levando-se também em consideração o fator ambiental, o etanol é consideravelmente menos tóxico que o metanol e pode ser obtido pelo processamento de materiais renováveis [5]. Portanto, para um país com elevadas produções de etanol, o uso deste álcool é economicamente e ambientalmente favorável.

Quando se considera o processo de transesterificação em meio básico para a produção de biodiesel, a acidez maior que $1 \%$ favorece a formação do sabão [6], indesejável no processo. Como uma alternativa para tal empecilho, o uso primeiramente de uma reação de esterificação em meio ácido seguida da transesterificação em meio básico poderia auxiliar na obtenção do biodiesel sem a formação de sabão [7], uma vez que os ácidos presentes no início da reação já terão sido convertidos em ésteres. Portanto a simulação testada envolverá ambos os processos: de esterificação seguida de transesterificação.

O uso da modelagem a partir dos dados experimentais obtidos para a etapa de esterificação, permite predizer o comportamento da reação. Utilizando o Software Aspen Plus V8.4 foi possível realizar a modelagem da cinética da reação de esterificação com o modelo Powerlaw, presente no programa, além da simulação do processo, sendo importante para a análise das condições necessárias, demandas, equipamentos e resultados. 


\section{Experimentos}

Inicialmente foi verificada a possível vantagem em utilizar álcool 8:2 molar ao invés de 9:1 molar [2]. Para tal foi simulado no programa Aspen Plus V8.4 a separação utilizando coluna de destilação do tipo RadFrac além do reciclo do etanol para o reator.

Verificadas as condições, foram realizados experimentos em laboratório para análise das condições de reação para a esterificação. Foram variadas temperatura, razão molar etanol/ácido láurico, quantidade de catalisador além de testar o comportamento da reação para diferentes ácidos. Uma vez obtidos os dados, realizou-se a regressão dos mesmos utilizando modelo Powerlaw com a mesma ferramenta computacional utilizada para simular a destiladora para reciclo do etanol. Com a regressão, foram obtidos os valores da constante cinética e energia de ativação que melhor ajustassem tais dados.

Uma vez simulada a reação de esterificação, pôde-se simular o restante do processo em si, iniciando com a reação de esterificação, separação dos produtos formados e reaproveitamento do etanol utilizado, a neutralização do catalisador ácido, transesterificação básica e a purificação do biodiesel formado.

Ao longo da simulação foram utilizados caixas de manipuladores Design-Spec, que regulam entradas ao longo do processo, de modo a poder alterar automaticamente diferentes entradas no caso de desejar-se variar valores e especificações ao longo do processo, facilitando a manipulação do programa.

\section{Resultados e Discussão}

Antes de realizar os primeiros experimentos e a modelagem, foi verificado se haveria grande diferença na utilização da proporção etanol/água 9:1 molar ou 8:2 molar, portanto foi simulado no programa Aspen Plus V8.4 quais seriam as condições necessárias para a recuperação do etanol na composição desejada utilizando-se uma coluna de destilação, pois o destilado seria reciclado novamente para o processo. Neste caso foi desconsiderada a presença de outros componentes além de água e etanol. Os resultados encontrados estão na Tabela 1.

Tabela 1 - Resultados obtidos para separação etanol/água em diferentes proporções

\begin{tabular}{|c|c|c|}
\hline & Proporção 9:1 molar & Proporção 8:2 molar \\
\hline Razão de Refluxo & 7,6 & 0,87 \\
\hline Número de Pratos & 65 & 12 \\
\hline Razão molar saída de etanol (topo)/entrada & 0,95 & 0,999 \\
\hline
\end{tabular}

Como pode ser observado, a separação utilizando uma proporção etanol/água de 9:1 demandaria uma coluna muito maior, elevando por consequência o seu custo, além de apresentar uma razão de refluxo muito superior e com menor recuperação e saída de etanol para o reciclo.

Uma vez obtidos tais resultados, constatou-se que para a separação e reciclo de etanol para o processo, o uso do álcool a $80 \%$ seria vantajosa, porém deveria-se ainda verificar qual o impacto da presença de maior quantidade de água na reação de esterificação.

Por meio de experimentos realizados em laboratório, pôde-se verificar qual a influência das proporções testadas. A diferença entre as conversões e tempo para a reação atingir o equilíbrio podem ser observadas na Figura 1. 


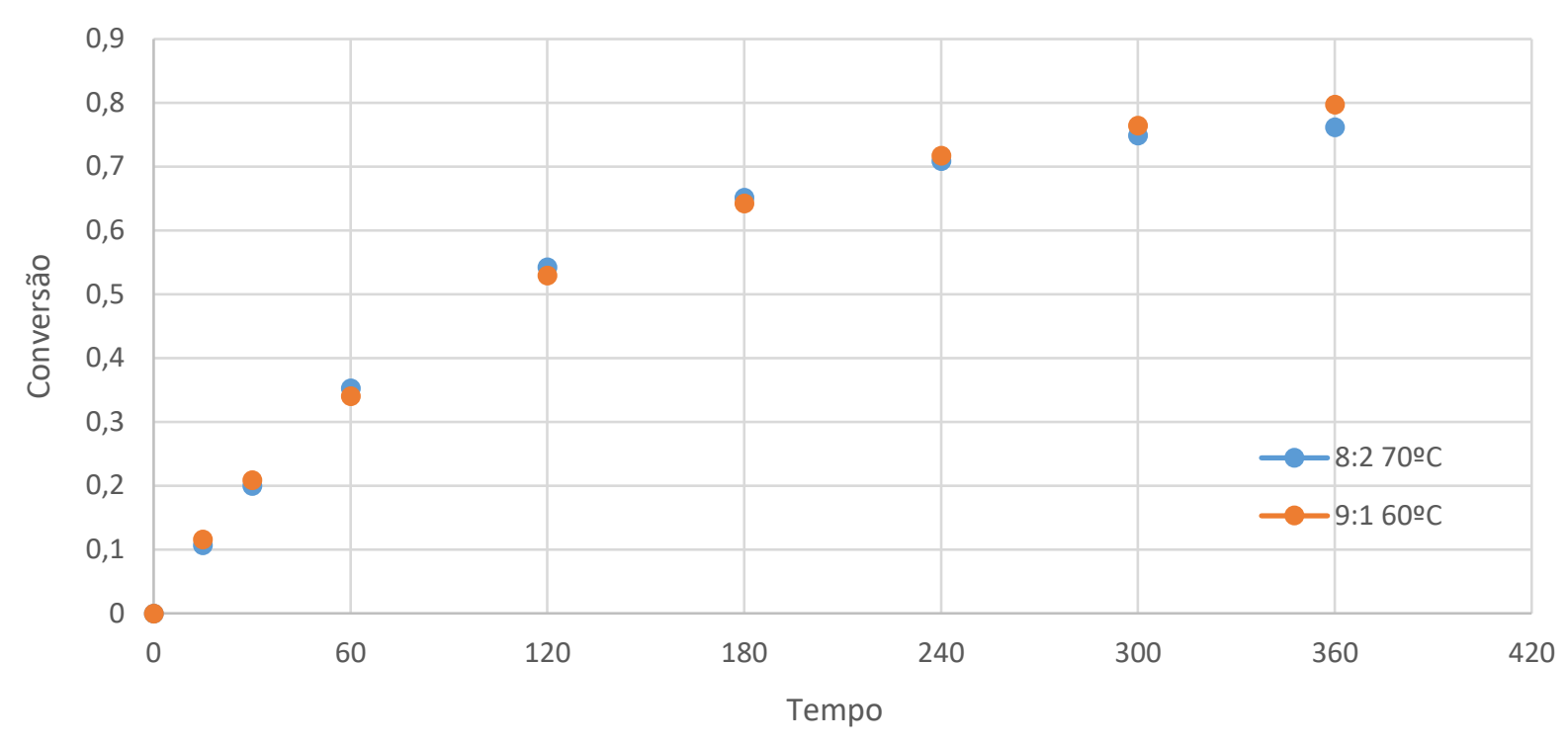

Figura 1 - Conversões obtidas para diferentes proporções etanol/água e temperaturas

Portanto pode-se observar que embora a conversão da proporção 9:1 (81\%) seja maior que a de 8:2 (76\%) e a uma temperatura pouco menor, analisando a diferença da conversão, ainda é válido considerar uma possível vantagem do uso da proporção menor de etanol devido aos custos relativos ao processo de destilação na recuperação do etanol.

Uma vez verificado que há a possibilidade de realizar tal processo utilizando etanol $80 \%$ molar, foram realizados os experimentos para análise e escolha das condições que proporcionariam melhores conversões. Portanto para a etapa de modelagem, foram realizados previamente testes variando temperatura de reação, quantidade de catalisador, razão etanol/ácido, podendo ressaltar que também foram testados diferentes tipos de ácidos que poderiam se encontrar no óleo utilizado para a conversão em biodiesel, sendo que os três ácidos testados apresentaram comportamentos semelhantes, optando portanto em utilizar o ácido láurico para os demais testes, por apresentar fácil manipulação, elevada pureza e melhor conhecimento das contaminações presentes.

Após obtidos os dados necessários, foi utilizado o método Powerlaw presente no Software Aspen Plus para realizar a regressão dos mesmos. A equação referente ao método citado encontra-se na Eq. 1.

$$
\mathrm{k}_{\mathrm{n}}=\exp \left(\frac{\mathrm{E}_{\mathrm{n}}}{\mathrm{R} \cdot \mathrm{T}}\right)
$$

Sendo k a constante cinética da reação, n o número da reação (direta 1 e inversa 2), E a energia de ativação, $\mathrm{R}$ a constante dos gases ideais e $\mathrm{T}$ a temperatura.

Porém, para que possa ser realizada a regressão, foi necessário obter a fração molar de ácido presente na reação em diferentes tempos.

Para o cálculo da fração molar, determinou-se primeiramente a porcentagem de ácido graxo livre na amostra seguindo a normatização da "AOCS Official Method" Ca 5a-40 pela Eq. 2.

$$
\operatorname{FFA}(\%)=\frac{\mathrm{V}_{\mathrm{NaOH}} \cdot \mathrm{N} . \mathrm{MM}_{\text {ácido graxo }}}{\mathrm{m}_{\text {alíquota }}}
$$

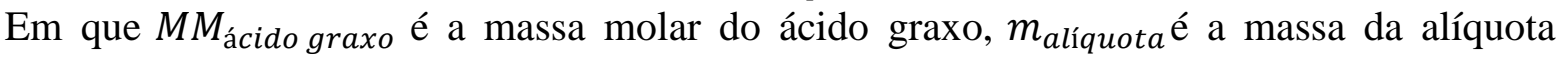
retirada na amostragem e $\mathrm{N}$ a molaridade, determinada a partir de padronização com biftalato de potássio, de acordo com a normatização da AOCS Specification H 12-52.

Uma vez obtidas as porcentagens de ácido graxo livre, foram calculadas as frações molares em cada tempo, inserindo os resultados no programa. Colocados os dados obtidos no programa, foi especificado que deveria-se encontrar os valores da energia de ativação e constante cinética que melhor ajustassem os pontos anteriormente inseridos.

Foram testadas diferentes estimativas iniciais para verificar o resultado da convergência que resultasse no menor valor da função objetivo. Os resultados estão apresentados na Tabela 2. 
Tabela 2 - Resultados do ajuste dos dados

\begin{tabular}{|c|c|c|}
\hline $\mathrm{E}_{1}$ & $11,732 \pm 0,044$ & $\mathrm{kcal} / \mathrm{mol}$ \\
\hline $\mathrm{E}_{2}$ & $4,340 \pm 0,151$ & $\mathrm{kcal} / \mathrm{mol}$ \\
\hline $\mathrm{k}_{1}$ & $85122,081 \pm 5668,060$ & $\mathrm{~m}^{3} / \mathrm{kmol} . \mathrm{s}$ \\
\hline $\mathrm{k}_{2}$ & $1,121 \pm 0,247$ & $\mathrm{~m}^{3} / \mathrm{kmol} . \mathrm{s}$ \\
\hline
\end{tabular}

Determinados os valores necessários, os mesmos foram utilizados para simular o processo utilizando o Software Aspen Plus V8.4. O fluxograma do processo proposto se encontra na Figura 2.

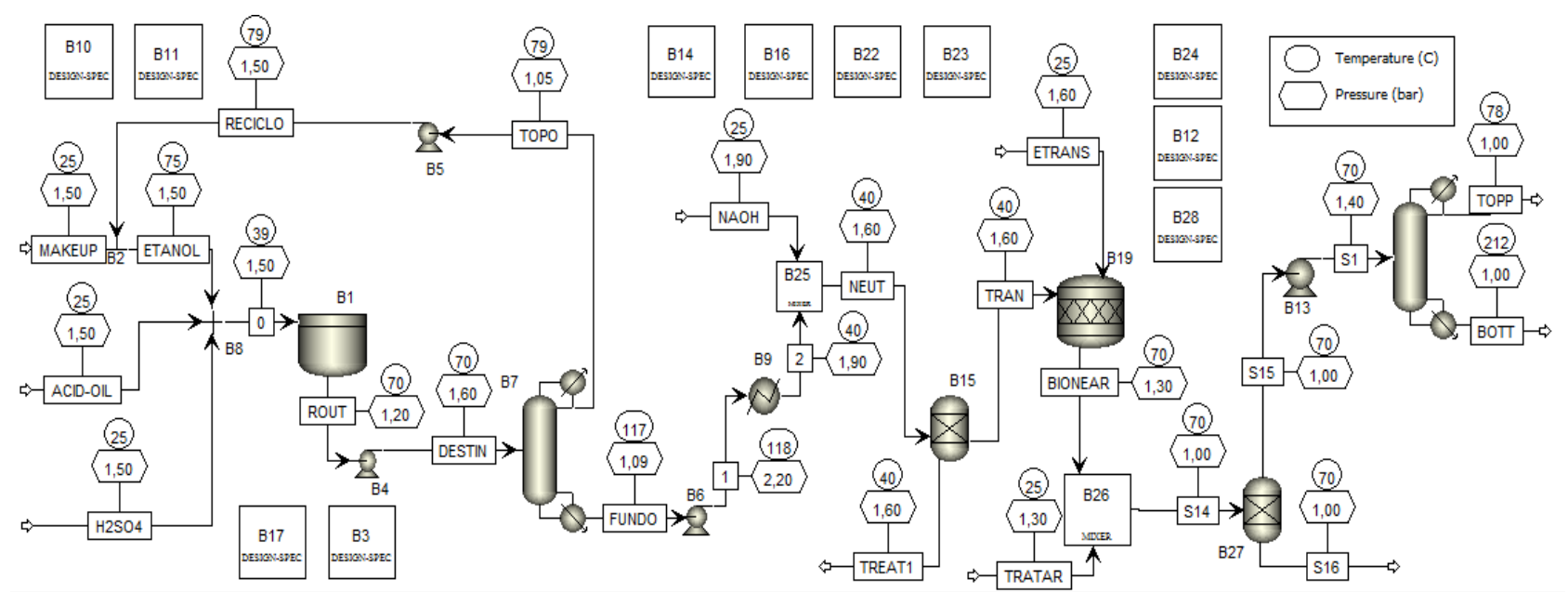

Figura 2 - Fluxograma do processo de produção de biodiesel

O processo proposto é constituído de um reator em batelada de esterificação ácida, seguido pela coluna de destilação para o reciclo do etanol remanescente. O topo, rico em etanol retorna para a entrada do processo como reciclo, a corrente de fundo, rica em água, reagentes remanescentes e produtos formados, é encaminhada para a neutralização com hidróxido de sódio. O sal formado é retirado do processo, podendo seguir assim para o reator de transesterificação básica. Os produtos formados são levados para uma nova neutralização com ácido sulfúrico, separando em seguida o sal formado e a glicerina. Por fim, o etanol, água, a trioleína não reagida e os componentes do biodiesel são separados na última destiladora, restando como produto de fundo o biodiesel com pequena contaminação de trioleína e como produto de topo o etanol com água.

Com relação aos reagentes inseridos no reator, foi estipulada uma entrada de trioleína, com a presença de $10 \%$ de ácido láurico em relação à quantidade de trioleína. Como fora determinada por experiências em laboratório, uma proporção de etanol/ácido de 9:1 é adequada e o álcool possui a presença de água na proporção 8:2. Porém, para que se facilite o manuseio do programa para diferentes proporções e entradas, foram utilizados Design-Spec (representadas por caixas sem correntes conectadas), que estão distribuídos ao longo da simulação. As caixas B10 e B11 são utilizadas para modificar, respectivamente, a quantidade de etanol e água presentes na corrente MAKEUP, de modo que a corrente ETANOL contenha sempre as proporções adequadas dos reagentes, portanto a entrada do reator não ficará comprometida ainda que haja alguma variação no reciclo ou na entrada do óleo na corrente ACID-OIL.

Do mesmo modo, as caixas B3 e B17 foram utilizadas para regular a entrada de catalisador ácido, enquanto uma controla a quantidade de ácido presente em $\mathrm{H} 2 \mathrm{SO} 4$, que corresponde a 0,33\% em massa da corrente de entrada do reator, a outra controla a quantidade de água presente, correspondente a $2 \%$.

A corrente indicada como 0 na realidade é inexistente, mas foi inserida devido a entrada do reator no simulador permitir apenas uma corrente de entrada, com isso, no processo real deveria haver duas correntes de entrada, uma para a corrente contendo o óleo ácido e outra contendo o etanol com o catalisador. 
Com os dados obtidos por meio de laboratório, foi criada a reação de esterificação utilizando os valores da energia de ativação e constante cinética. No primeiro reator, foi especificada a reação de esterificação e as condições desejadas (temperatura $70^{\circ} \mathrm{C}$ e perda de carga de 0,3 bar). As perdas de carga foram determinadas a partir de regras heurísticas.

A destiladora segue o reator de esterificação e para esta foi adotado o modelo RadFrac. As informações inseridas e testadas foram o número de estágios necessários, o tipo de evaporador e condensador e o número do estágio de alimentação. Em seguida foram utilizados os Design Specifications da própria coluna, em que o programa deveria variar a razão de refluxo e a vazão de destilado de modo a se obter uma recuperação de etanol no topo de 99,9\% e a razão etanol/água de 8:2. Com isso foi obtida uma coluna contendo 10 pratos, uma vazão de destilado de $177 \mathrm{Kg} / \mathrm{h}$ (corrente ETANOL deverá possuir $195 \mathrm{Kg} / \mathrm{h}$ ) e uma razão molar de refluxo de 0,12 , menor em relação aos testes envolvendo a separação exclusivamente do etanol e água, possivelmente devido à interação dos produtos formados e reagentes restantes no sistema. Também é válido ressaltar que as perdas de carga consideradas na coluna foram de 0,1 bar para condensador e refervedor e 0,035 bar por prato. Tal perda por prato considerada foi estimada a partir de um valor intermediário de perdas de carga em relação ao tipo de prato utilizado, uma vez que não foi especificado um tipo específico de prato para a coluna.

As utilidades usadas para o condensador e refervedor foram, respectivamente, água de resfriamento (entrada $30^{\circ} \mathrm{C}$ e saída a $40^{\circ} \mathrm{C}$ ) e vapor pressurizado a 2,7 bar.

$\mathrm{O}$ produto de fundo da coluna é então neutralizado com hidróxido de sódio. Para controlar a quantidade correta de $\mathrm{NaOH}$ foram usados dois blocos Design-Spec, o B14 e B16. O primeiro controla a quantidade de $\mathrm{NaOH}$ na corrente de mesmo nome para neutralizar o ácido sulfúrico completamente e sem excessos. A segunda controla a quantidade de água que deverá entrar juntamente com a base em sua solubilidade. O sal formado é então retirado da corrente juntamente com a água necessária para a solubilização do sulfato de sódio, correspondente a aproximadamente 50 gramas de $\mathrm{Na}_{2} \mathrm{SO}_{4}$ em 100 gramas de água [8]. O equipamento para tal separação foi um Sep, o qual é utilizado para simplificar a separação de componentes presentes em uma corrente, podendo assim focar a maior complexidade no restante do processo.

Uma vez que o equipamento Sep é apenas uma simplificação de um processo mais complexo de separação, não foi considerada perda de carga, assumindo que ao final da separação, a pressão fosse elevada novamente ao mesmo valor da entrada no equipamento.

Em seguida a corrente seguirá para o reator de transesterificação em meio básico, portanto a segunda corrente de entrada no reator é composta por etanol, água e hidróxido de sódio, todos controlados por Design-Spec. Como esta corrente conterá três componentes, há também três caixas de especificação, a B22, B23 e B24. A primeira controlará a entrada de etanol em função da quantidade de trioleína na proporção etanol/trioleína de 6:1, sendo que neste quesito é importante ressaltar que o uso de excesso de álcool é muitas vezes vantajosa por facilitar a reação, porém o uso deste excesso é recomendado em razões máximas de álcool:óleo de 12:1, uma vez que para razões superiores, a separação do glicerol formado é dificultada [9]. A segunda controlará a vazão de hidróxido de sódio, equivalente a 1,5\% em massa, da vazão total de trioleína e etanol das correntes TRAN e ETRANS, respectivamente. A terceira tem a função de regular a entrada de água juntamente com o etanol. Para este caso foi considerado etanol anidro, uma vez que não foi realizado um estudo em laboratório para verificar a influência da presença de água na reação de transesterificação, portanto utilizou-se um álcool de maior pureza, mais comum na literatura. Com isso, a quantidade de água estipulada foi de $0,2 \%$ da vazão de etanol.

A conversão de trioleína em etil oleato adotada foi de 97\% [10], restando ao final do processo uma sobra de pouco mais de $25 \mathrm{~kg} / \mathrm{h}$ de trioleína. No reator é utilizado vapor de baixa pressão, presente no banco de dados do Aspen Plus. Após a transesterificação a corrente é neutralizada com ácido sulfúrico e os cristais do sal formado são retirados do processo pelo equipamento Sep, onde também há a retirada de glicerina para facilitar o posterior processo de destilação. Na neutralização também são utilizadas caixas de Design-Spec para controlar a quantidade de ácido utilizada para a 
neutralização do hidróxido de sódio e a quantidade de água presente no ácido, representadas pelas caixas B28 e B12, respectivamente.

Ao final, é utilizada uma destiladora RadFrac para a separação do etanol e água restantes, que saem pelo topo, do biodiesel contaminado com trioleína, que sai pelo fundo. Inicialmente foi testado o processo com uma destiladora do tipo DSTWU a fim de ter-se uma estimativa para a inserção dos dados na destiladora RadFrac. Nesta coluna foram adotados 4 estágios, condensador total e refervedor tipo Kettle. A alimentação ocorre no terceiro estágio, a utilidade especificada no condensador é a mesma que a utilizada na primeira destiladora e para o refervedor será utilizado vapor de alta pressão, utilidade presente no banco de dados do Aspen. Nesta coluna foi feita a especificação da recuperação de etanol no topo, correspondente a 97,5\% variando a razão de destilado em relação à alimentação. Como resultado, foi obtida uma razão molar de destilado de 0,4763 em relação à entrada da coluna. A razão molar de refluxo adotada foi de 1,16, por ser a menor razão de refluxo necessária para uma separação eficiente do produto final evitado também a secagem de pratos.

O produto de fundo contém aproximadamente $875 \mathrm{~kg} / \mathrm{h}$ de etil oleato, $78 \mathrm{~kg} / \mathrm{h}$ de etil laurato e $25,73 \mathrm{~kg} / \mathrm{h}$ de trioleína, portanto há a produção de cerca de uma tonelada de biodiesel a uma pureza de $97 \%$, superior à especificada pela ANP, de 96,5\% em ésteres.

\section{Conclusões}

O processo de esterificação mostrou-se com uma conversão adequada ainda que houvesse a presença de uma maior quantidade de água. Mesmo com a necessidade de uma temperatura de $10^{\circ} \mathrm{C}$ maior para se atingir uma conversão semelhante à da proporção etanol:água de 9:1, a análise da separação do etanol para o reciclo se mostrou vantajosa para a proporção 8:2, com número de pratos cinco vezes menor, baixa razão de refluxo (aproximadamente 9 vezes menor) e maior recuperação deste para retornar ao processo. Para a etapa de transesterificação, por sua vez, foi utilizado uma maior quantidade de hidróxido de sódio como catalisador, a fim de evitar o uso de grandes quantidades de etanol, proporcionando uma maior conversão da trioleína presente e simplificando a etapa de separação ao final do processo, que separa o etanol e água do biodiesel, o qual possui pureza de $97 \%$, atendendo a especificação da ANP com relação à presença de ésteres, assim como a especificação relacionada à presença de água, de no máximo 500 ppm, sendo que no produto final haverá a presença de apenas $45 \mathrm{ppm}$.

As condições do processo demonstram a necessidade do uso de utilidades em ambas as destiladoras e nos reatores, mas grande parte do processo possui condições brandas, com baixas pressões e temperaturas amenas, podendo-se utilizar vapores e água de resfriamento.

As taxas de conversão tanto na etapa de esterificação quanto de transesterificação são altas (76\% na esterificação e $97 \%$ na transesterifiação), resultando em uma elevada vazão de biodiesel obtida ao final, correspondente à aproximadamente uma tonelada. Também pode-se observar que o processo não apresenta elevada complexidade e o uso do simulador é vantajoso para a identificação de possíveis aperfeiçoamentos para a redução de custos ou ainda a alteração de especificações e condições para as desejadas.

A simulação realizada, portanto, visa contribuir na visualização e manipulação do processo em si, podendo-se ter uma visão crítica sobre os tipos de equipamentos necessários, condições e complexidade do processo. É possível também realizar a variação de condições, verificando assim se as condições testadas poderão contribuir para uma maior pureza, recuperação ou custos envolvidos.

\section{Agradecimentos}

Agradecimentos à Fundação Araucária, Secretaria de Estado da Ciência, Tecnologia e Ensino Superior (SETI-PR) e ao Governo do Estado do Paraná, pelo apoio financeiro recebido para viabilizar esta participação. 


\section{Referências}

[1] SALLET, L. CÍNTIA, ALVIM M. AUGUSTO. Biocombustíveis: uma análise da evolução do biodiesel no Brasil. Economia \& Tecnologia, 2011, v. 25, p. 3.

[2] MURAD, P.C., Hamerski, F., Corazza, M.L. et al. Estudo de Viabilidade da Produção de Biodiesel via Esterificação de Óleo Ácido. Tese de mestrado. Universidade Federal do Paraná, 2017.

[3] RAMOS, L. P. et al. Biodiesel: Raw Materials, Production Technologies and Fuel Properties. Rev. Virtual Quim., 2017, v. 9, n. 1, p. 317-369.

[4] PEREIRA A. LUCAS. et al. Metanol e etanol em esterificação e transesterificação simultâneas do óleo de palma hidrolisado com estearato de zinco comercial. XXIV ENCONTRO DE QUÍMICA DA REGIÃO SUL, Florianópolis, 2017.

[5] B.H. HAMEED, L.F. LAI, L.H. CHIN. Fuel Process. Technol., 90 (2009), pp. 606-610.

[6] GOMES, M. M. R. Produção de biodiesel a partir da esterificação dos ácidos graxos obtidos por hidrólise de óleo de peixe. Tese de mestrado. Universidade Federal do Rio de Janeiro, 2009.

[7] SHEREENA, K. M. et al. Biodiesel: an Alternative fuel Produced From Vegetable Oils by Transesterification. Electronic Journal of Biology, 2009, v. 5, n. 3, p. 67-74.

[8] WELLS, C. R. Sodium Sulfate: Its sources and uses. Ohio State University, 1923.

[9] MUSA, I. A. The effects of alcohol to oil molar ratios and the type of alcohol on biodiesel production using transesterification process. Egyptian Journal of Petroleum, 2016, v. 25, n. 1, p. 2131.

[10] SILVA, J. G. da, ANDRADE LIMA, L. R. P. de, \& TORRES, E. A. Cinética Da Transesterificação Etílica Do Óleo De Algodão Herbáceo. Anais Do XX Congresso Brasileiro de Engenharia Química, 2014. 